\title{
Tarub sebagai sumber belajar biologi keanekaragaman hayati dan konservasi berbasis kearifan lokal budaya Jawa
}

\author{
Milade Annisa Muflihaini a, ${ }^{*}$, Suhartini ${ }^{\text {b, } 2}$ \\ a Pendidikan Biologi Pascasarjana, Universitas Negeri Yogyakarta \\ b Jurusan Pendidikan Biologi, FMIPA, Universitas Negeri Yogyakarta \\ Karangmalang, Yogyakarta, 55281 \\ 1 miladeannisa.2018@student.uny.ac.id*;2 suhartini@uny.ac.id \\ *korespondensi penulis
}

\begin{abstract}
Abstrak
Artikel ini adalah hasil studi literatur (literature review) dengan menggunakan metode pendekatan deskripsi kualitatif yang bertujuan untuk mengetahui dan mendeskripsikan potensi Tarub sebagai sumber belajar biologi dalam mengenalkan keanekaragaman hayati dan konservasi melalui kearifan lokal budaya Jawa. Pada Tarub, terdapat beberapa komponen seperti bleketepe, tuwuhan (hasil bumi) yang terdiri dari berbagai macam objek tumbuhan yang dapat diidentifikasi sebagai bahan dalam pembelajaran biologi terutama pada keanekaragaman tumbuhan. Pemanfaatan potensi ini berperan penting dalam upaya konservasi biodiversitas.
\end{abstract}

Kata kunci: tarub, keanekaragaman hayati, konservasi, kearifan lokal, sumber belajar biologi,

\section{Abstract}

This article is the result of a literature review study using a qualitative description approach method that aims to identify and describe the potential of Tarub as a source of learning biology in introducing biodiversity and conservation through local wisdom of Javanese culture. At Tarub, there are several components such as bleketepe, tuwuhan (crops) consisting of various kinds of plant objects which can be identified as ingredients in biology learning, especially on plant diversity. Utilization of this potential plays an important role in biodiversity conservation efforts.

Keywords: tarub, biodiversity, conservation, local wisdom, biology learning resources

\section{PENDAHULUAN}

Indonesia merupakan Negara yang terkenal dengan keanekaragaman pulau dan budayanya. Salah satu pulau yang memiliki beragam budaya dan adat istiadat adalah Pulau Jawa. Di Pulau jawa, dalam kehidupan sehari-harinya memiliki ciri khas budaya seperti pada pernikahan. Bagi masyarakat Jawa, pernikahan merupakan suatu acara yang agung dan penuh kesakralan sehingga diselenggarakan berbagai upacara dengan banyak makna dan simbol yang memiliki nilai filosofi tinggi. Upacara pernikahan tersebut dimulai dari Nontoni, Nembung, Pasang Tarub, Midodareni, Akad nikah, Panggih, Balangan suruh, Ngidak endhok (menginjak telur), Wiji dadi, Timbangan, Kacar-kucur, Dulangan, Sungkeman, Kirab, 
Jenang sumsuman, dan Ngundhuh manten. Salah satu upacara dari rangkaian upacara tersebut yang paling banyak menggunakan bahan atau hasil bumi adalah pasang Tarub. Namun, dewasa ini Masyarakat Jawa terkadang tidak mengetahui makna filosofi simbolsimbol yang terdapat di dalam alat-alat maupun bahan yang digunakan di dalam upacara pemasangan Tarub. Kurangnya pemahaman masyarakat mengenai makna-makna tersebut dapat dikarenakan rendahnya rasa handarbeni (memiliki) dan konservasi budaya, sehingga lama kelamaan dapat mengakibatkan menurunnya nilai-nilai luhur yang diangkat melalui kearifan lokal budaya setempat. Disisi lain, fenomena budaya pada pemasangan Tarub ini dapat dimanfaatkan sebagai potensi kearifan lokal yang sangat mendukung untuk dijadikan sumber belajar khususnya pada cabang ilmu pengetahuan Biologi, dimana Biologi adalah ilmu yang memiliki ciri menggunakan benda hidup sebagai obyek studinya (IGP Surya Darma, dkk, 1997:5)/ mempelajari tentang mahkhluk hidup dan fenomena yang melekat pada kehidupannya. pada Biologi adalah

Berdasar latar belakang tersebut, maka diperlukan adanya pengkajian terhadap potensi kearifan lokal budaya Jawa, yaitu melaui pemaknaan "Tarub" sebagai salah satu sumber belajar biologi dan konservasi berbasis kearifan lokal, sehingga dalam artikel ini akan dibahas mengenai "Tarub" dan bagian-bagiannya serta pemaknaannya sebagai bahan ajar dalam mengenalkan keanekaragaman hayati dan konservasinya yang berbasis kearifan lokal.

\section{METODE}

Metode yang digunakan pada penelitian ini adalah metode literature review dengan pendekatan deskriptif kualitatif. Teknik pengumpulan datanya berupa kajian pada artikelartikel yang relevan dengan Tarub dan potensinya sebagai sumber belajar berbasis kearifan lokal, dan melalui observasi atau pengamatan langsung Tarub yang dipasang dalam upacara pernikahan di masyarakat Jawa, dengan mengambil sampel lokasi Daerah Istimewa Yogyakarta.

Keanekaragaman hayati dan konservasinya pada penelitian ini meliputi bahan-bahan yang dipergunakan dalam pemasangan Tarub dan kearifan lokal dalam penelitian ini adalah nilai yang diajarkan oleh para leluhur atau nenek moyang dalam dalam memelihara dan memanfaatkan sumberdaya alam secara berkelanjutan., sumber belajar biologi yang dimaksud dalam penelitian ini mengangkat nilai-nilai kearifan lokal masyarakat budaya Jawa dalam upaya konservasi biodiversitas dengan mengkaji nilai kearifan lokal dan diidentifikasi sesuai kebutuhan pembelajaran Biologi diversitasi (Biodiversitas). 


\section{HASIL DAN PEMBAHASAN}

Tarub adalah bangunan sementara, atau tratag untuk tamu. Tarub juga dapat diartikan dari akronim bahasa Jawa yaitu "Ditata supaya murup" yang berarti diatur atau ditata agar bersinar. Tarub dahulu dibuat oleh para tetangga dan sanak keluarga pengantin, dibuat beberapa hari sebelum pernikahan dan tetap dipasang selama upacara-upacara pernikahan, merupakan sesaji kepada Tuhan untuk keselamatan upacara pernikahan, sehingga memberikan makna filosofi rasa syukur kepada Tuhan Yang Maha Esa, dan tanda isyarat kepada tetangga juga sanak saudara bahwa akan diadakan adat Budaya pemasangan tarub.

Pemasangan tarub bersamaan dengan bleketepe dan tuwuhan, ketiganya menjadi kesatuan. Tarub terdiri dari Bleketepe dan tuwuhan. Tuwuhan, daun-daun dan buah-buahan digantung di kiri dan kanan gerbang atau jalan masuk, di rumah atau tempat pernikhan. Arti tuwuhan ini secara keseluruhan adalah baik "kemakmuran tanaman maupun harapan kemakmuran bagi calon keluarga yang baru" (Adat dan Upacara Perkawinan Daerah Istimewa Yogyakarta, 1977/1978: 48). Kata tuwuhan berasal dari kata tumbuhan, merupakan lambang pengantin sudah berubah menjadi dewasa dan harus meninggalkan pemikiran masa muda; juga kedudukannya dalam masyarakat sudah berubah menjadi keluarga batih dan mereka harus bertanggung jawab untuk akibatnya.

\section{Potensi Tarub dan makna filosofinya sebagai sumber belajar biologi berbasis kearifan lokal}

Potensi Tarub sebagai sumber belajar biologi memiliki kekhasan tersendiri dibanding dengan sumber belajar lainnya, karena Kearifan lokal merupakan potensi yang harus dipertahankan dan dikembangkan serta dimanfaatkan (Wikantiyoso dan Tutuko, 2009:7). Pemanfaatan lingkungan didalam proses pembelajaran biologi akan lebih bermakna karena diperoleh dari fenomena yang bersifat aktual dan alami yang dapat diamati langsung di kehidupan sehari-hari. Demikian dengan adanya Tarub, yang dapat diamati ketika adanya hajatan upacara pernikahan di masyarakat Jawa. Secara umum, Tarub dihiasi dengan bleketepe dan tuwuhan (hasil bumi) yang terdiri dari janur, pisang raja, tebu, godhong opoopo (dedaunan apa saja), pari sewuli dan cengkir gading. Masing-masing bahan yang diperoleh dari sumber daya alam hayati di kehidupan sehari-hari masyarakat ini memiliki nilai filosofi masing-masing. Berikut ini merupakan ringkasan uraian makna filosofi dari bahan-bahan yang digunakan dalam Tarub dari berbagai kajian: 
1. Janur (daun kelapa yang masih muda, berwarna hijau muda kekuning-kuningan).

Filosofi: Suatu cita-cita yang mulia untuk menggapai cahaya Illahi dengan hati suci untuk mengharapkan keberkahan-Nya.

2. Pisang Raja (Pisang raja yang digunakan jenis Pisang raja ayu atau Pisang raja madu sebanyak 2 tandan)

Filosofi: Pisang raja mempunyai rasa yang manis, sehingga nantinya kedua mempelai dapat mengarungi bahtera rumah tangga dengan manis. Jumlah tandan pisang berarti, doa agar mempelai dapat memberikan keturunan yang banyak, atau diberkahi kehidupan rumah tangganya depan diberikan momongan oleh Tuhan.

3. Tebu (Tebu yang digunakan dapat jenis tebu wulung atau tebu arjuna, beserta daunnya)

Filosofi: Tebu = antebing kalbu (singkatan dari bahasa jawa), yaitu kedua orang tua mempelai sudah ikhlas, rela, mantap untuk melepaskan anak-anaknya untuk menempuh hidup baru. Tebu jenis ini pun merupakan tebu jenis pilihan dan unggul, sehingga maknanya orang tua mengharapkan mempelai yang menikah dapt menjadi contoh atau teladan yang baik bagi orang terdekat maupun disekitar lingkungannya nanti.

4. Cengkir Gading (jenis kelapa dengan buahnya yang berwarna kuning).

Filosofi: Cengkir = kencenging pikir $($ singkatan dari bahasa jawa), yang mempunyai makna kesatuan maksud tekadnya sudah bulat. Selain itu, buah cengkir gading dalah buah yang dapat digunakan sebagai obat atau penangkal racun, maknanya kedua orangtua dari mempelai berharap anak-anaknya sudah bulat dalam tekad untuk membangun rumah tangga dengan segala resiko yang akan dihadapi ke depan.

5. Pari sewuli (Padi seuntai)

Filosofi: symbol pangan, agar mempelai nantinya diberikan kecukupan pangan dalam kehidupan berumah tangga.

6. Daun Randu (diambil dari pohon kapuk randu)

Filosofi: simbol sandang, agar mempelai nantinya diberikan kecukupan sandang dalam kehidupan berumah tangga.

7. Godhong Opo-Opo (berbagai macam dedaunan)

Macam-macam daun yang digunakan adalah:

a. Daun Beringin.

Filosofi: melindungi. Suami sebagai kepala keluarga dapat melindungi keluarganya dan memberikan contoh pada masyarakat dalam membina keluarganya dengan baik. 
b. Daun Kluwih.

Filosofi: linuwih-luwih (dari bahasa jawa luwih dengan imbuhan in), berarti "lebih", yaitu bentuk harapan untuk mempelai agar memiliki nilai lebih ketika sudah menempuh hidup baru, dalam berbagai hal seperti wawasan, ilmu kehidupan, semuanya meningkat dan bertambah baik.

c. Daun Alang-Alang, Daun Kara Dan Daun Maja.

Filosofi dari ketiga daun ini adalah agar kehdupan berumah tangga mempelai, terhindar dari berbagai rintangan dan halangan.

d. Daun Kemuning dan Daun Girang.

Filosofi: kebahagiaan. Harapannya mempelai dapat selalu menciptakan suasana bahagia dalam menempuh hidup baru.

Melihat objek atau bahan yang digunakan dalam Tarub ini menggunakan bahan alam yaitu tumbuh-tumbuhan, dan masing-masing memiliki filosofinya dapat berpotensi digunakan dalam sumber belajar biologi.

\section{Kaitan Tarub dan Keanekaragaman spesies pada biologi diversitas}

Berdasarkan bahan-bahan tersebut, maka dapat digunakan sebagai sumber belajar untuk mengenalkan keragaman spesies tumbuhan di Indonesia berbasis kearifan lokal daerah setempat yaitu pada budaya Jawa. Berikut merupakan jenis-jenis tumbuhan yang digunakan sebagai bahan-bahan dalam pembuatan Tarub

Tabel 1. Spesies Komponen Tarub

\begin{tabular}{ccc}
\hline Komponen Tarub & \multicolumn{2}{c}{ Nama } \\
\cline { 2 - 3 } Janur / Daun kelapa yang muda & Lokal/Indonesia & Ilmiah \\
Daun beringin & Kelapa & Cocos nucifera L. \\
Daun kluwih & Beringin & Ficus benjamina L. \\
Daun kara & Kluwih & Artocarpus camansi \\
Daun maja & Kara, Kara benguk & Mucuna pruriens \\
Daun Alang-alang & Maja & Aegle marmelos L. Corr \\
Daun randu & Alang-alang & Imperata cylindrica L. Beauv \\
Daun girang & Randu, Kapuk randu & Ceiba pentandra L \\
Daun kemuning & Girang & Leea aequata L. \\
Cengkir gadhing & Kemuning & Murraya paniculata $L$. \\
Setandan buah pisang raja & Kelapa gading & Cocos nucifera var. Eburnea \\
Sepasang Tebu beserta daunnya & Pisang raja & Musa paradisiaca var. Raja \\
Pari sewuli (Padi seuntai) & Tebu wulung/arjuna & Saccharum officinarum \\
\end{tabular}

Menggunakan informasi dari tabel tersebut, maka dapat digali informasi-informasi keanekaragaman hayati dan konservasi berbasis kearifan lokal. Seperti pada kelapa gading, 
pembelajar dapat mengetahui bahwa pada spesies ini merupakan flora identitas dari Kota Yogyakarta (Keputusan walikotamadya Yogyakarta No 2 Tahun 1998).

\section{SIMPULAN}

Tarub merupakan salah satu upacara dari serangkaian upacara adat pernikahan budaya Jawa yang dapat digunakan sebagai sumber belajar biologi, terutama pada keanekaragaman hayati. Menggunakan berbagai bahan-bahan dari tumbuhan dan memiliki nilai filosofi masing-masing, merupakan sebuah potensi bahwa tarub dapat digunakan dalam membelajarkan keanekaragaman hayati, yaitu keanekaragaman tumbuhan serta konservasinya berbasis kearifan lokal. Kearifan lokal yang ada dalam masyarakat Jawa berperan penting dalam upaya konservasi biodiversitas,

\section{REFERENSI}

Adam, Rebecca. 2001. Upacara Pernikahan di Jawa, Upacara-Upacara, Simbolisme, dan Perbedaan Daerah di Pulau Jawa. ACICIS: Fakultas FISIP. Universitas Muhammadiyah Malang, Jawa Timur.

Ahmadi, I., Amri, S. dan Elisah T. (2012). Mengembangkan Pendidikan Berbasis

Asmani, J.M. (2012). Pendidikan Berbasis Keunggulan Lokal. Jogjakarta: Diva Press.

Aziz, Amelia Wahyu Wandicha Magel, 2017. Identifikasi nilai-nilai kearifan lokal masyarakat adat kampung naga sebagai sumber belajar biologi pada konsep biodiversita. Tesis diterbitkan dalam epository.upi.edu. Bandung: Universitas Pendidikan Indonesia.

Bonsai Tanaman. 2018. Mengenal ciri-ciri pohon beringin/Ficus benjamina. (Online), (http://tanamanbonsai.com/mengenal-ciri-ciri-pohon-beringinficus-benjamina/) diakses 22 Agustus 2019.

Departmen Pendidikan dan Kebudayaan, Pusat Penelitian Sejarah dan Budaya, Proyek Penelitian dan Pencatatan Kebudayaan Daerah. 1997/1998. Adat dan Upacara Perkawinan Daerah Istimewa Yogyakarta.

Femina. 2014. Ragam Kelapa. (Online), (https://www.femina.co.id/article/ragam-kelapa) diakses 22 Agustus 2019.

Jayanti, dkk. 2017. Analisis Kebutuhan Bentuk Sumber Belajar dan Media Pembelajaran Biologi Berbasis Potensi Lokal untuk Kelas X SMA di Provinsi Lampung. Makalah disajikan dalam Seminar Pendidikan IPA Pascasarjana UM. Malang, Vol.2.

Jayati, Ria Dwi dan Yunita Wardianti. 2018. Pembelajaran Biologi berbasis Kearifan Lokal di Kota Lubuklinggau. Makalah disajikan dalam National Conference on Mathematics, Science, Education (NACOMSE), Pamekasan, 22 Semptember 2018.

Keunggulan Lokal. Jakarta: Prestasi Pustaka

Magligai. 2007. Pernikahan Adat Jawa Solo. Jakarta: PT. Dwi Putra Glomedia. 
Munajah dan Muhammad Joko Susilo. 2015. Potensi Sumber Belajar Biologi SMA Kelas X Materi Keanekaragaman Tumbuhan Tingkat Tinggi di Kebun Binatang Gembira Lokal. JUPEMASI-PBIO. 1 (2). 184-187.

Orwa C, Mutua A, Kind R, Jamnadass R, Simons A. 2009. Agroforestree Database: a tree reference and selection guide version 4.0. World Agroforestry Centre, (Online), (http://www.worldagroforestry.org/af/treedb/.

Profil Keanekaragaman Hayati DIY Tahun 2016. (Online), (http://kehati.jogjaprov.go.id/detailpost/kelapa-gading) diakses 22 Agustus 2019.

Sudjana, N dan Rivai, A. 1989. Teknologi Pengajaran. Bandung: Sinar Baru.

Sudjoko. 2001. Membantu Siswa Belajar IPA. Yogyakarta: FMIPA UNY.

Wikantiyoso, R dan Tutuko, P. 2009. Kearifan Lokal dalam Perencanaan dan Perancangan Kota untuk Mewujudkan Arsitektur Kota yang Berkelanjutan. Malang: Universitar Merdeka Malang. 